\title{
New investigation of mechanical properties of a horizontal axis wind turbine blade based on a hybrid composites with kenaf fibers
}

\author{
Z. Belfkira $^{1}$ (1) H. Mounir ${ }^{1} \cdot$ A. El Marjani ${ }^{1}$
}

Received: 12 October 2019 / Accepted: 8 January 2020 / Published online: 18 January 2020

(c) Springer Nature Switzerland AG 2020

\begin{abstract}
The present work aims to assess the benefit of introducing simultaneously kenaf and carbon fibers in a composite wind turbine blade made initially of epoxy glass fiber. After an in-depth analysis of the optimal design of the blade using the Blade Element Momentum theory, an algorithm is generated in order to, firstly, establish the foundation of the blade geometry and secondly, to make a conservative static loading estimation representing a 50-years extreme gust. After performing the blade geometry on the 3D-modeler CATIA ${ }^{\circledR} \mathrm{V} 5$, it was imported to PATRAN ${ }^{\circledR}$ software in order to create the mesh of the turbine blade. By modifying the way of stacking layups at each zone of the blade and by taking into account the plies properties, seven models were created. A further comparison was made between these models with a view of finding the best combination of fibers to satisfy the allowable thresholds. After several attempts of fibers combinations, it was finally revealed that the best way to combine the three fibers consists of replacing all unidirectional glass fibers of the blade skin with kenaf fibers and substituting those of the spar cap with carbon fibers while maintaining intact the remaining blade layups.
\end{abstract}

Keywords Kenaf fibers · Carbon fibers · Composites · Flexural rigidity · Flapwise deflection

$\begin{array}{ll}\text { List of symbols } \\ d T & \text { Differential thrust } \\ d P & \text { Differential power } \\ d C_{P} & \text { Differential power coefficient } \\ d F_{L} & \text { Elemental lift force } \\ d F_{D} & \text { Elemental drag force } \\ d Q & \text { Elemental torque } \\ C_{L} & \text { Lift coefficient } \\ C_{D} & \text { Drag coefficient } \\ \rho & \text { Air density } \\ \Omega & \text { Turbine angular velocity } \\ \omega & \text { Wind angular velocity } \\ R & \text { Wind turbine rotor radius } \\ d r & \text { Differential radius } \\ a & \text { Axial induction factor } \\ a^{\prime} & \text { Angular induction factor } \\ a_{c} & \text { Glauert axial induction factor limit }\end{array}$

$\gamma \quad$ Tip speed ratio

$\gamma_{r} \quad$ Tip local ratio

$V_{\infty} \quad$ Free stream wind velocity

$V_{\text {rel }} \quad$ Relative wind velocity

$V \quad$ Wind axial velocity

$c \quad$ Chord length

$\theta_{p} \quad$ Pitch angle

$F \quad$ Prandtl correction factor

$B \quad$ Number of the turbine blade

$\sigma \quad$ Solidity ratio

$E_{i} \quad$ Young modulus components

$v_{i j} \quad$ Poisson ratio components

$G_{i j} \quad$ Shear modulus components

$t_{\text {root }} \quad$ Root layups thickness

$v_{h} \quad$ Incoming flow velocity at the blade tip

$v_{h_{0}} \quad$ Incoming flow velocity at the hub height

$h$ Turbine rotor radius

Z. Belfkira, zakaria.belfkira@gmail.com | ${ }^{1}$ EMISys Research Team, E3S Research Center, Mohammadia School of Engineers, University Mohammed V in Rabat, B.P. 765, Avenue Ibn Sina, Agdal, Rabat, Morocco. 


$\begin{array}{ll}h_{0} & \text { Tower height } \\ y_{\text {Max }} & \text { Maximal tip deflection } \\ F_{\text {force }} & \text { Applied force } \\ E & \text { Effective Young modulus } \\ I & \text { Effective moment of inertia }\end{array}$

\section{Introduction}

The growth of the worldwide energy demand due to the high consumption rates has led to the depletion of fossil fuel reserves and has pushed many governments to formulate stricter regulations to limit greenhouse gas emissions. Hence, significant efforts were made to face these humanitarian challenges. Among the envisaged solutions, is looking for friendly and environmentally energy resources and boosting researches and innovations in the field of renewable energies. Wind energy, in particular, has shown spectacular increase in terms of installed capacity and investments [1, 2]. In fact, it is expected that by the year 2030, wind energy will respond to at least $20 \%$ of the U.S. energy needs [3]. The European Union has also set an ambitious goal and intent to ensure $20 \%$ of its energy needs focusing only on renewable energies $[4,5]$ and in the same context, wind energy is expected to grow with an annual rate of $21 \%$ [6-8].

In order to be more competitive, the wind energy industry should make more efforts to reduce the production cost. One way to achieve this goal is to increase the wind turbine radius because the generated power by a wind turbine is theoretically proportional to the square of its radius [9]. In face of this, the blade mass grows with respect to the cubical square of the turbine radius [9]. So to sort out this dilemma, other paths should therefore be explored such as looking for lightweight structural materials.

In many recent researches, lignocellulosic natural fibers were used as reinforcement for composites to benefit from their lightweight, biodegradability, low cost and good mechanical properties [10-12] and it has been shown that natural fibers can successfully replace synthetic fibers specially glass fibers [13-18]. Among the widely used natural fibers, kenaf has been considered as an ideal candidate to be used in hybrid composites [19]. Therefore, in this work kenaf fibers were chosen to be combined with synthetics fibers in order to take advantage from their multiple properties.

The turbine blade is the centerpiece of the turbine rotor, thus in this work many attempts were made to decrease the blade weight using a combination of natural and synthetic fibers whilst taking into consideration some allowable mechanical properties. Firstly, a glass reinforced plastic (GRP) turbine blade was performed using PATRAN $^{\circledR}$ software, this finite element model was made from unidirectional fiber $\left(0^{\circ}\right)$ in combination with double bias fabric $( \pm 45)$. Secondly, the GRP layups were modified by replacing, progressively, the $0^{\circ}$ glass fibers with carbon or kenaf fibers according to the blade parts.

Based on the BEM theory, aerodynamic forces were calculated following a conservative approach which consists of considering Class I site with a gust wind speed of $70 \mathrm{~m} / \mathrm{s}$ as shown in the International Electrotechnical Commission (IEC) requirements [20]. The blade was divided into eleven sections and aerodynamic loads were calculated for each station using the iterative approach of the BEM theory. The resulting loads were then conservatively applied to the extremity of the blade sections as shown on Fig. 15, this approach is considered the most commonly used method described in the literature [21]. After, results were evaluated according to the allowable tip deflection and to the flexural rigidities.

Many researches that study hybrid composites based on natural fibers were focused in particular on the combination of only two fibers [22-29]. Nevertheless, the main objective of this study is to find the ultimate combination between three kinds of fibers: Glass, carbon and Kenaf fibers. For that purpose, seven models were analyzed through this work: The first one is the reference model made entirely by glass fibers, for the second and the third models the blade skin was kept intact and all spar unidirectional glass fibers were replaced either by carbon fibers for the second model or by kenaf fibers for the third one. For the fourth and the fifth models, all unidirectional glass fibers in the initial model were replaced either by carbon fibers for the fourth model or by kenaf fibers for the fifth one. For the sixth model, skin material configuration of the fifth model was considered coupled with the spar of the second model. Finally, the seventh model has represented the optimal combination between the used fibers, such as it has had the same material configuration as the sixth model with the only difference that the spar web was kept intact compared to the baseline model.

With more than $55 \%$ of kenaf fibers weight ratio and taking into account the tip deflection allowable and the material cost, it was proved how the seventh model represents the adequate combination between the three kinds of fibers.

\section{Theoretical model}

\subsection{BEM theory}

The Blade Element Momentum theory is a widely recognized and practical method used for design optimization and for calculating aerodynamic forces acting on a wind 
turbine blade. This method is a combination between the momentum and the blade element theories [30].

\subsubsection{Momentum theory}

The momentum theory consists of analyzing the change rate of momentum in the flow passing through the rotor plane of the wind turbine. This theory is often started by a simple approach which assumes that the turbine rotor can be assimilated to a circular disc composed of an infinite number of blades or what is commonly called in literature the actuator disc illustrated in Fig. 1 and described in $[30,31]$.

The actuator disc theory allows calculating the maximum power coefficient $C_{p \max }$ or the so-called Betz limit that is equal to $\frac{16}{27}$ [31]. This value means that the power extracted from the air cannot exceed $59.3 \%$ of the available power. In fact, the air exiting the turbine rotor has a rotational motion because of the reaction to the torque exerted on the rotor by the incoming flow, thus the previous assumptions should be extended to take into account the wake rotation. Figure 2 describes the shape of the real trajectory of an air particle passing through the rotor disc.

To analyze the wake rotation, the flow domain should be split into many annular stream tubes and by applying the conservation of the angular and axial momentum theories as well as the Bernoulli's equations, the differential power and the thrust at the rotor turbine can be given by the following equations:

$d T=\rho V_{\infty}^{2} 4 \pi r a(1-a) d r$

$d P=\Omega^{2} \rho 4 \pi r^{3} a^{\prime} V_{\infty}(1-a) d r$

where $\Omega$ is the turbine angular velocity, $d r$ is the differential radius, $v_{\infty}$ is the velocity of the incoming flow, $\rho$ is the air density, $a$ and $a^{\prime}$ are respectively the axial and angular induction factors defined as follows:

$a=\frac{V_{\infty}-V}{V_{\infty}}$

$a^{\prime}=\frac{\omega}{2 \Omega}$

where $V$ and $\omega$ are respectively the axial and the angular velocity of the wind at a distance $r$ from the center of the rotor disc. Two other dimensionless parameters are commonly defined at this section: the tip and local speed ratios defined by the following formula:
$\gamma=\frac{\Omega R}{V_{\infty}}$ and $\gamma_{r}=\frac{\Omega r}{V_{\infty}}$

where $R$ is the rotor radius.

The differential power coefficient is then calculated as follows:

$d C_{P}=\frac{d P}{\frac{1}{2} \rho \pi r^{2} V_{\infty}^{3}}$

\subsubsection{The blade element theory}

The blade element theory is the second half of the BEM theory which tries to introduce the blade geometry into the process of the design determination, this theory is based on two suppositions:

- The turbine blade can be split into many elements which are aerodynamically independents

- The forces acting on each blade element are solely determined by the drag and the lift coefficients.

Figure 3 shows a blade element extracted from a zone of analysis.

There are two categories of aerodynamic forces acting on the turbine blade, the drag force or the forces acting parallel to the wind flow direction and the lift force or the forces acting perpendicular to the incoming flow direction. Figure 4 depicts the aerodynamic forces acting on a blade element.

Where $\alpha$ is the angle of attack, $\phi$ is the angle between the direction of the incoming flow and the rotor plane, $\theta_{p}$ is the pitch angle. The lift and drag forces are defined through the following equations.

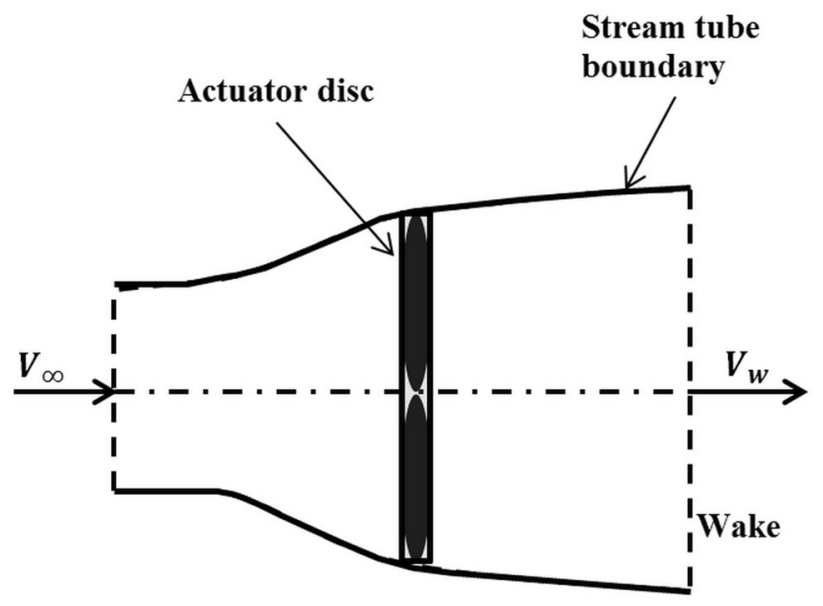

Fig. 1 Actuator disc model for a wind turbine 
Fig. 2 The wake rotation and the annular stream tube
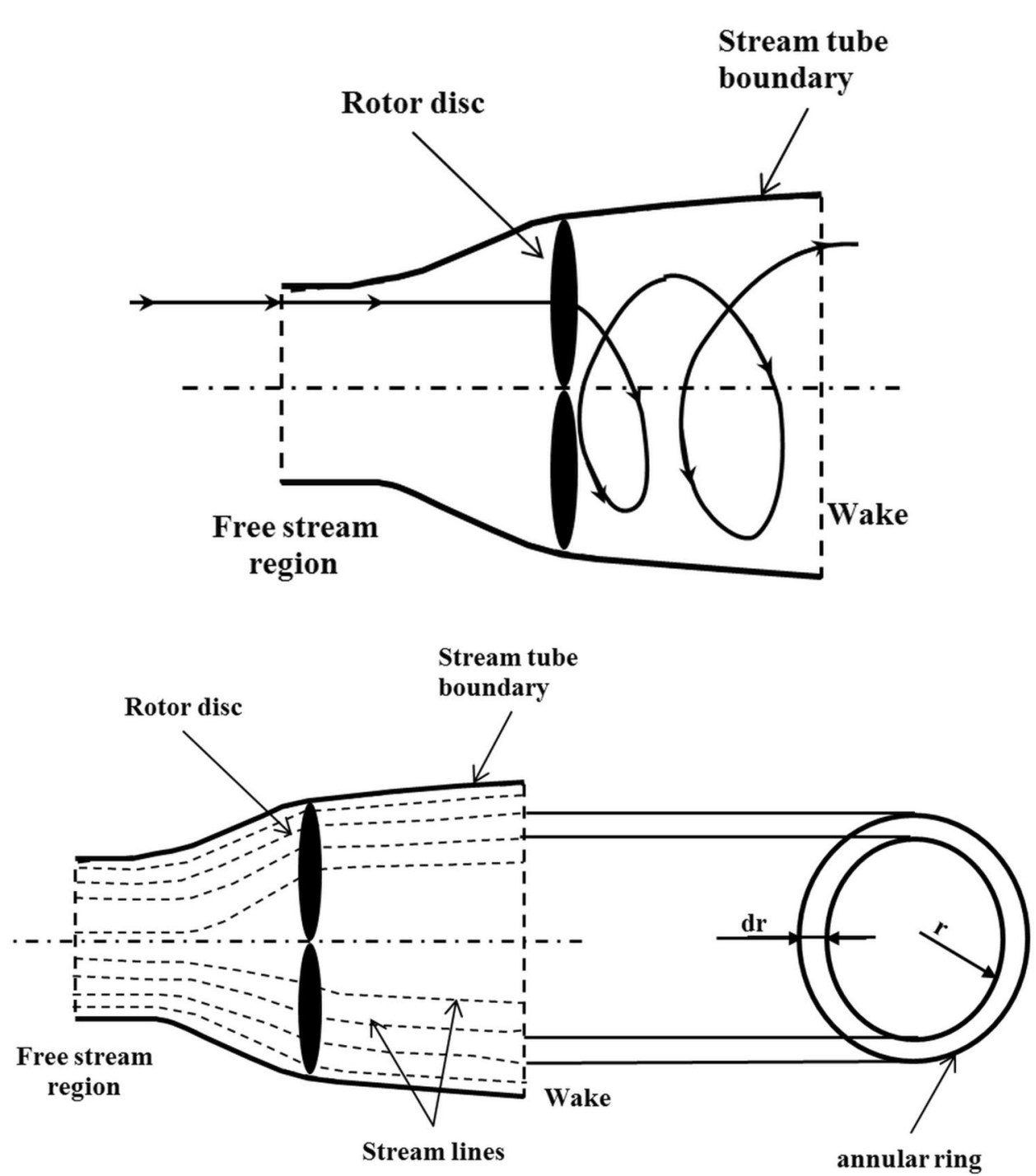

Stream tube

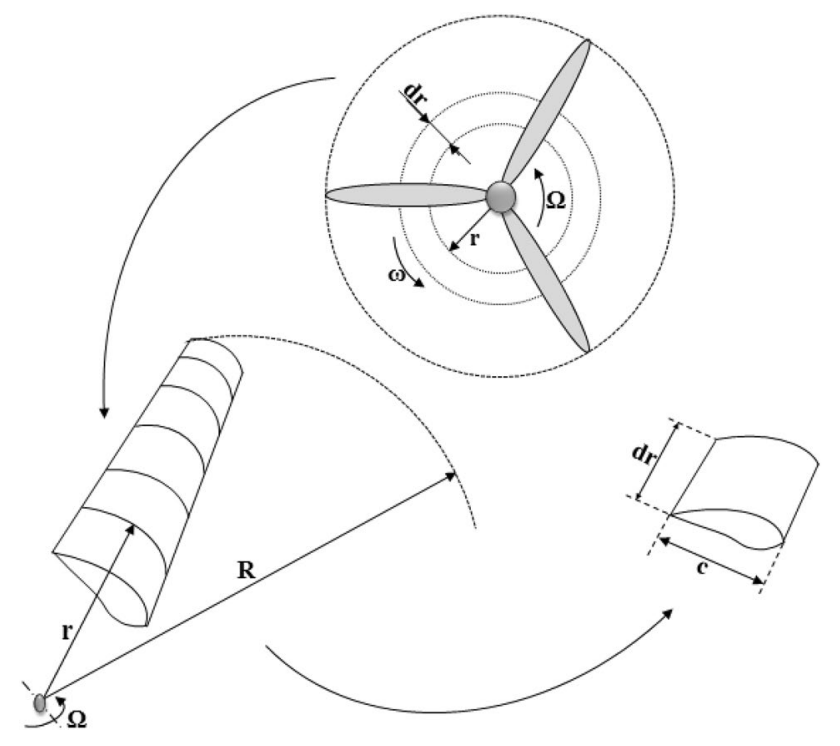

Fig. 3 Blade element of an annular ring

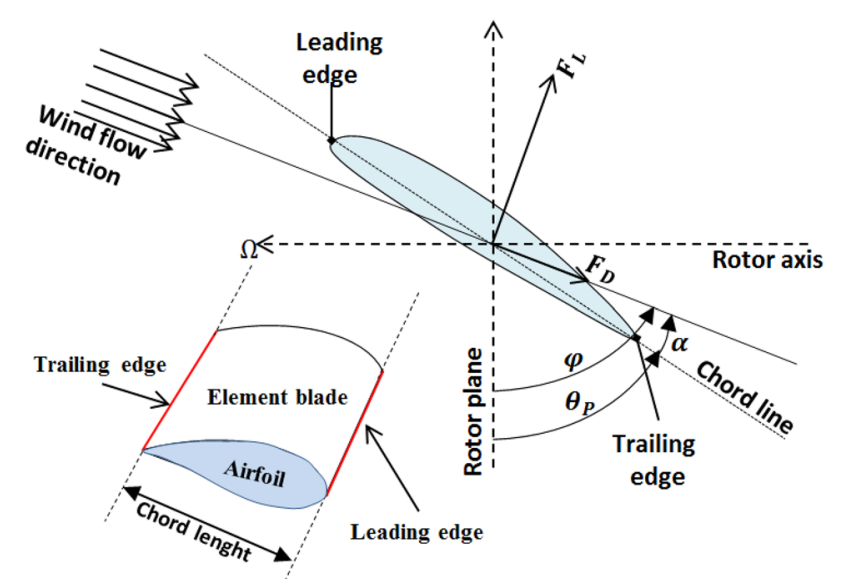

Fig. 4 Blade element forces 
$d F_{L}=C_{L} \times 1 / 2 \times \rho \times V_{r e l}^{2} \times c \times d r$

$d F_{D}=C_{D} \times 1 / 2 \times \rho \times V_{r e l}^{2} \times c \times d r$

$C_{L}$ and $C_{D}$ are, respectively, the lift and drag coefficients, $c$ is the chord length and $V_{\text {rel }}$ is the relative wind velocity defined as shown on (9):

$V_{r e l}=\frac{V_{\infty}(1-a)}{\sin (\phi)}$

For the purpose of completing the blade element theory, two correction factors have to be considered in the analysis: Tip-loss and Glauert correction factors.

The power production is more influenced by the induced velocity near the tips due to the vortices generated by the blade tips into the wake [30], so to deal with this deficiency Prandtl has defined a correction factor $F$ as shown in (10):

$F=\frac{2}{\pi} \cos ^{-1} e^{-f} ; \quad f=\frac{B}{2} \frac{R-r}{r \sin (\phi)}$

where $B$ is the number of the turbine blades.

When the values of the axial induction factor exceed approximately $a_{c}=0.2$, the momentum theory is no longer valid [32], thus to remedy this problem, Glauert introduces some empirical equations to calculate the axial induction factor when $a>a_{c}$ as shown in (11):

$a=\frac{1}{2}\left[2+K\left(1-2 a_{c}\right)-\left\{\left(K\left(1-2 a_{c}\right)+2\right)^{2}+4\left(K a_{c}^{2}-1\right)\right\}^{1 / 2}\right]$

$K=\frac{4 \sin (\phi)^{2} F}{\sigma\left(C_{L} \cos (\phi)+C_{D} \sin (\phi)\right)}$ and $\sigma=\frac{B C}{2 \pi r}$

where $\sigma$ is known as the solidity ratio [33].

By equating and examining different equations of both momentum and blade element theories, following equations can be established:

$$
\begin{aligned}
& d T=F \sigma \pi \rho \frac{V_{r e l}^{2}(1-a)^{2}}{\sin (\phi)^{2}} r\left(C_{D} \sin (\phi)+C_{L} \cos (\phi)\right) d r \\
& d Q=F \sigma \pi \rho \frac{V_{r e l}^{2}(1-a)^{2}}{\sin (\phi)^{2}} r^{2}\left(C_{L} \sin (\phi)-C_{D} \cos (\phi)\right) d r \\
& a=\frac{1}{1+\frac{F 4 \sin (\phi)^{2}}{\sigma\left(C_{L} \cos (\phi)+C_{D} \sin (\phi)\right)}}
\end{aligned}
$$

$a^{\prime}=\frac{1}{\frac{F 4 \sin (\phi) \cos (\phi)}{\sigma\left(C_{L} \sin (\phi)-C_{D} \cos (\phi)\right)}-1}$

where $d T$ is the elemental thrust and $d Q$ is the elemental torque.

\subsubsection{The procedure of the blade design}

Based on the equations of the BEM theory an algorithm can be deduced in order to perform the blade design and to calculate the aerodynamic forces acting on the wind turbine. The design procedure supposes that some parameters are known as the rotor blade $R$, the number of blades $B$, the wind velocity $V_{\infty}$, the turbine angular velocity $\Omega$, lift coefficient $C_{L}(\alpha)$ and drag coefficient $C_{D}(\alpha)$.

Using Visual Basic for Excel, the steps of the obtained algorithm were programmed such as for each blade element, elemental aerodynamic characteristics were determined. At the beginning, the axial and angular induction factors were initialized, then the algorithm was executed to recalculate the values of $a$ and $a^{\prime}$. These steps were continuously repeated until reaching convergence according to an error rate fixed in advance.

\section{The model of analysis}

\subsection{Blade geometry}

The geometrical characteristics of the turbine blade such as the optimum chord length, pitch angle and the attack angle were determined following the iterative approach of the BEM theory, The blade design was then developed based on these optimal results.

\subsubsection{Blade skin geometry}

The turbine blade design was performed using NACA 63-618 as profiles section [34, 35]. This choice was made to more closely match the design of an actual wind turbine G52-850 KW of SIEMENS-GAMESA company [36].

Based on the geometrical characteristics resulting from the BEM theory, the 3-D modeler CATIA ${ }^{\oplus} \mathrm{V} 5$ was used to generate the cross-sections of the blade turbine. Figure 5 shows the geometry of the analyzed blade with a length of $26 \mathrm{~m}$. 

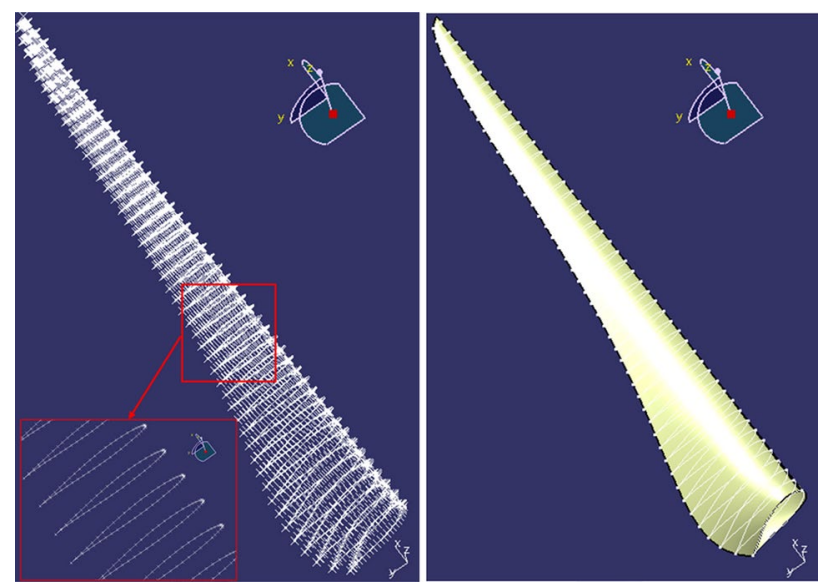

Fig. 5 Blade geometry

\subsubsection{Spar geometry}

As conventionally used for the wind turbine blade design [37], in this work the spar beam has a square shape. This box-shaped beam is composed by two verticals sides also called shear webs and two upper and lower sides known as the spar caps whose role is to provide the strength and bending stiffness requirements of the blade. Figure 6 shows a typical cross section of the analyzed blade.

\subsection{Material properties}

Many investigations were carried out toward the development of wind turbine materials [38]. In this work, three types of fibers have been combined with each other: E-Glass, carbon and kenaf fibers with the objective to benefit from their particular properties. On the one hand the combination of fiberglass with carbon fibers can be used to reach high structural performance [39-43], on the other hand, fiber glass is the synthetic fiber mostly used in the hybridization of natural fibers $[44,45]$.

\subsubsection{Fibers properties}

- E-glass fibers

The electric glass or the E-glass fibers are the most widely used fibers in low to medium performance composites. Glass fibers have generally a diameter in the order of 10 to $20 \mu \mathrm{m}$; they are characterized by low thermal coefficient, high electric resistance, larger elongation at failure and moderate stiffness and density $[46,47]$.

\section{- Carbon fibers}

The carbon fibers are the most commonly used fibers for high performance composites [46], they are composed almost of pure carbon [48-50]. Due to the shape of its crystallographic microstructure, carbon fibers could reach high mechanical properties and show higher stiffness and lower density compared with the glass fibers. Carbon fibers are widely used by companies specialized in wind turbines production such as SIEMENS-GAMESA and VESTAS.

\section{- Kenaffibers}

Kenaf fibers are considered among the most used natural fibers as reinforcement in composite structures [51-54]. Compared with other natural fibers [55] and based on many studies, kenaf fibers have always shown

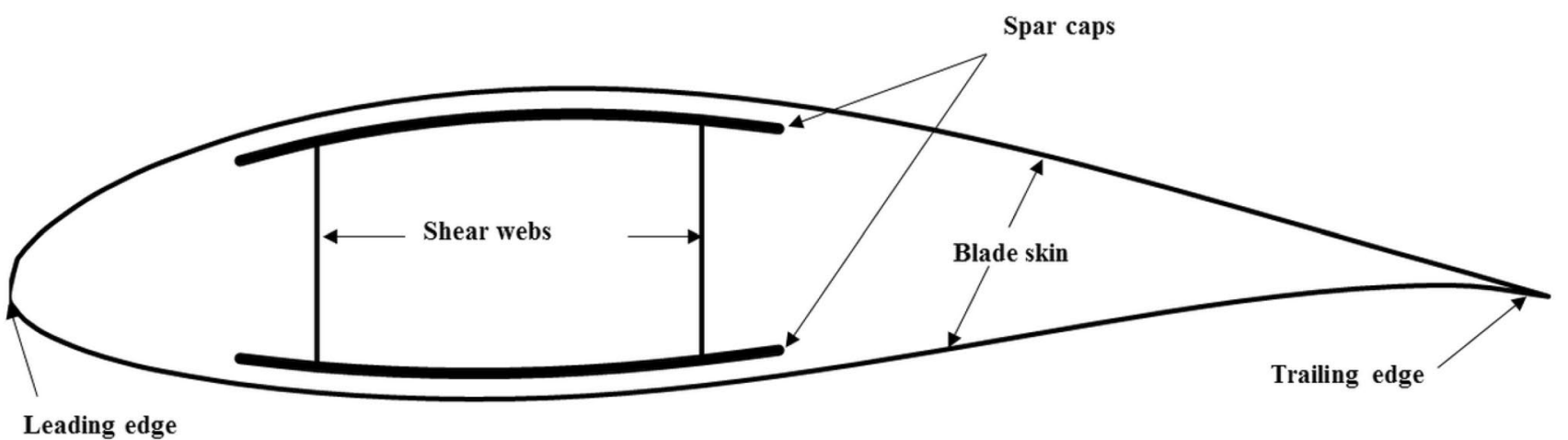

Fig. 6 Typical blade cross section 
good mechanical properties, thermal stability and a strong fiber-matrix adhesion [56-59] [19], especially when submitted to chemical treatments [60].

\subsubsection{Computed models layups}

\section{- Baseline model}

The baseline blade considered in this analysis is a 26 meters blade with NACA 63-618 as profiles sections. As explained in Sect. 3.1, the design of the baseline blade is the result of the iterative approach of the BEM theory. The baseline model is a E-glass/epoxy composite model composed with two types of glass fibers: The A130 used for the unidirectional fibers and the DB120 used for the $\pm 45^{\circ}$ directions, in addition to the glass fibers, Balsa wood was introduced in the trailing edge to enhance the capacity of buckling and to reduce the blade weight. Materials properties are extracted from [61] and summarized in the table below:

Based on the layups schemes and the location of each zone, the blade model can be divided into seven areas: A circular root section or the junction zone of the blade to the turbine hub, the leading and trailing edges, the blade tip section, the spar cap and the middle skin sections, the spar web area and the blade tip section. Figure 7 depicts these different areas:

The root section has the maximum layup thickness [62, $63]$, the root thickness is calculated based on the following formula [64].

$t_{\text {root }}=0.08 \times \sqrt{\frac{R}{40}}$

where $R$ is the turbine radius and $t_{\text {root }}$ is the root thickness calculated in meters.

The blade was divided into eleven sections; each section has its special properties in terms of layups thickness

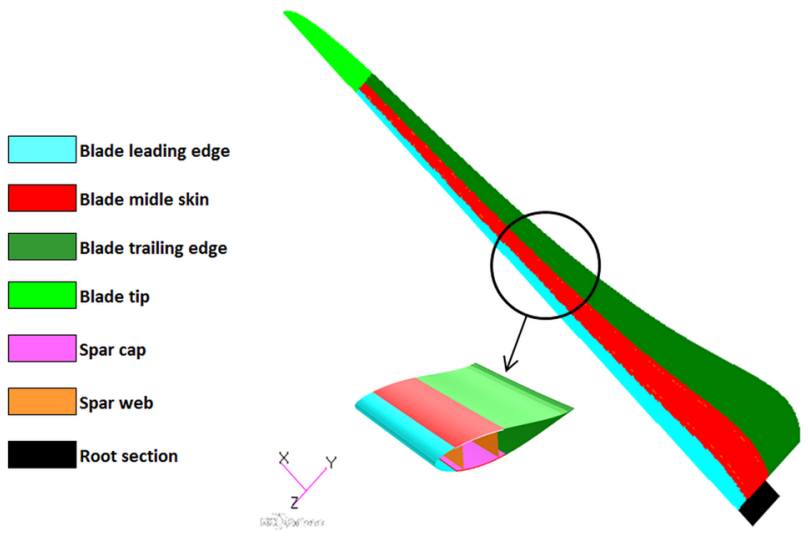

Fig. 7 Wind turbine blade components

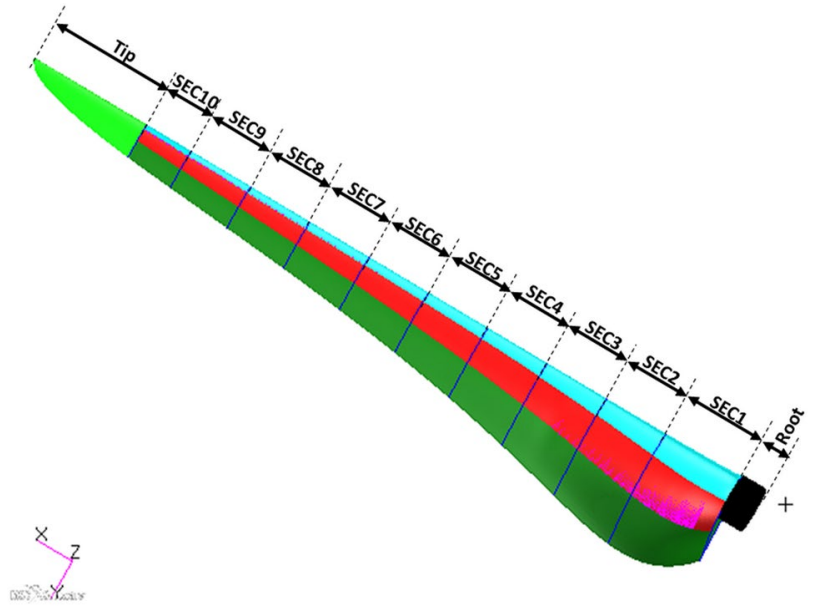

Fig. 8 Different sections of the blade

and material properties. Ten sections composed with spar cap, trailing and leading edges, spar web and blade middle skin and a last section which represents the tip blade. Each blade section consists of a region with constant layups thickness. Figure 8 illustrates these regions.

The thickness of the blade sections was sequentially reduced along the blade length with a reduction rate of about $3.6 \%$ between two successive sections, beginning with a thickness of $63 \mathrm{~mm}$ at the root and ending with a thickness of $13 \mathrm{~mm}$ at the blade tip.

For a given section, the middle skin and the spar cap have the same thickness and the same layups schedule, the leading edge has approximately the third of the thickness of the middle skin, whereas the trailing edge is considered as a sandwich layups with balsa wood which is used as a filler materiel to reduce the probability of buckling while decreasing the weight of the blade, the thickness of the trailing edge is nearly equal to the one of the middle skin. Finally, the spar web layup considered to have a constant thickness of about $12 \mathrm{~mm}$ along the blade spar.

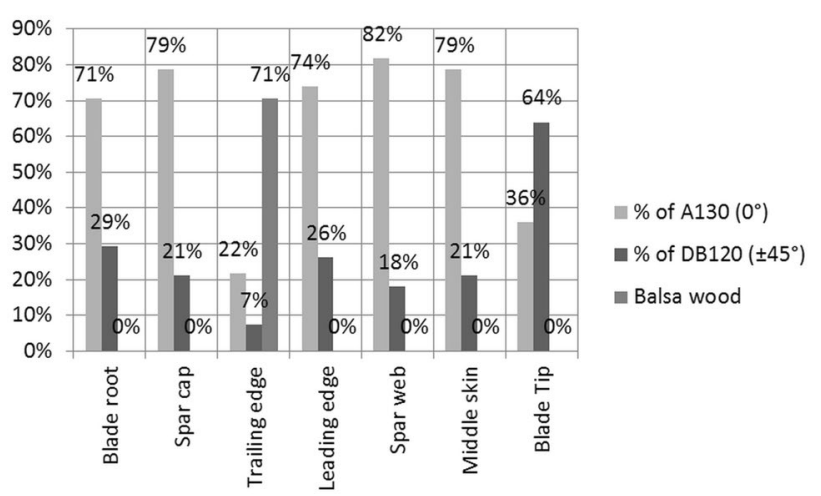

Fig. 9 Materials distribution along the baseline blade 


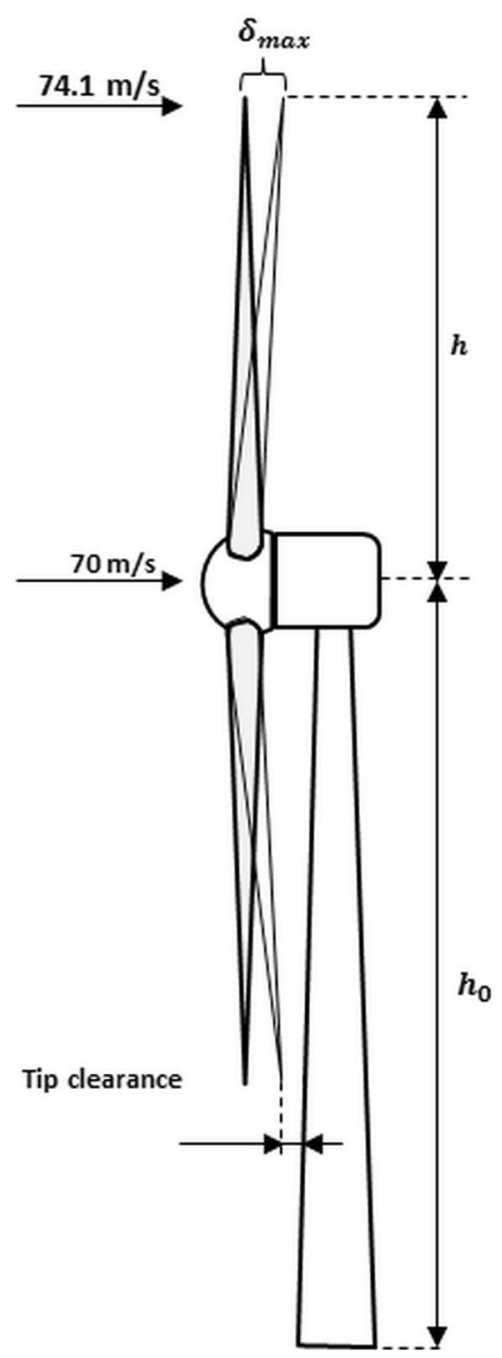

Fig. 10 Maximum gust loading along the blade span

The sections layups were composed by alternating double bias layers $\pm 45^{\circ}$ of DB120 and unidirectional layers of A130 following the same logic as mentioned in [61]. Figure 9 depicts the percentage of the thickness of each type layers in the layups schedule.

\section{- Models of analysis}

To benefit from the biodegradability, the lightweight, the low cost and the good mechanical properties of kenaf fibers [65] and the high performances of carbon fibers, six different layup schemes were evaluated. The analyzed models represent a modified version of the baseline model following the procedure explained in Table 2, such as each model was designed to study the effect of introducing the new materials shown on Table 3 on the blade structure. Each model was created based on the assumption that only unidirectional fibers were replaced either with carbon or with kenaf fibers, bias layers $\pm 45^{\circ}$ did not change. The choice of replacing only the $0^{\circ}$ plies was made because from a manufacturing point of view the $0^{\circ}$ carbon and kenaf fibers are more convenient than the $\pm 45^{\circ}$ fibers and their manufacturing costs is lower. Table 2 explains in details the zones affected by this changes.

Material properties of carbon and kenaf fibers used through this analysis are extracted respectively from [61] and [66] and depicted in Table 3.

\section{Computational procedure}

\subsection{Loading approximation}

In order to be conservative, the sizing load case used in this work corresponds to a severe loading of class I of the IEC standard [20]. This extreme loading represents a hurricane gust wind expected in a period of 50 year with $70 \mathrm{~m} / \mathrm{s}$ as wind velocity at the hub height. It is assumed that the load case resulting from these conditions is applied to a parked rotor with the consideration that the turbine blade is at its uppermost vertical position; it is also supposed that the local maximum lift coefficient is reached at each blade section and the blade displacement is entirely in the flapwise direction. According to the IEC requirements, the wind speed increases above the blade height according to the following equation:

$$
\frac{v_{h}}{v_{h_{0}}}=\left(\frac{h}{h_{0}}\right)^{0.14}
$$

where $v_{h_{0}}$ and $v_{h}$ are respectively the velocity at the hub height and at the blade tip, the 0.14 is a wind shear coefficient determined based on the IEC standard. Figure 10 illusrates the different dimensions shown on Eq. 18.

According to Fig. 4, the maximum flapwise bending will occur from the maximum lift force generated at each blade station. Therefore, based on the results of the BEM theory developed through Sect. 2.1, the lift force was calculated at 49 positions along the blade span while varying the incoming flow velocity following Eq. 18. Figure 11 shows the distribution of this force along the blade span.

From Fig. 11 the maximum lift force can be calculated for each section of Fig. 8, figure hereafter (Fig. 12) depicts the resulting forces.

\subsection{Finite element modelling}

\subsubsection{Meshed models and elements properties}

Once the geometry is performed, the surface model is exported to PATRAN ${ }^{\circledR}$ to generate a finite element shell 
Fig. 11 Maximum lift force distribuation along the blade span

Fig. 12 Maximum lift force distribuation along the blade span

Fig. 13 Stacking sequence based on the element normal

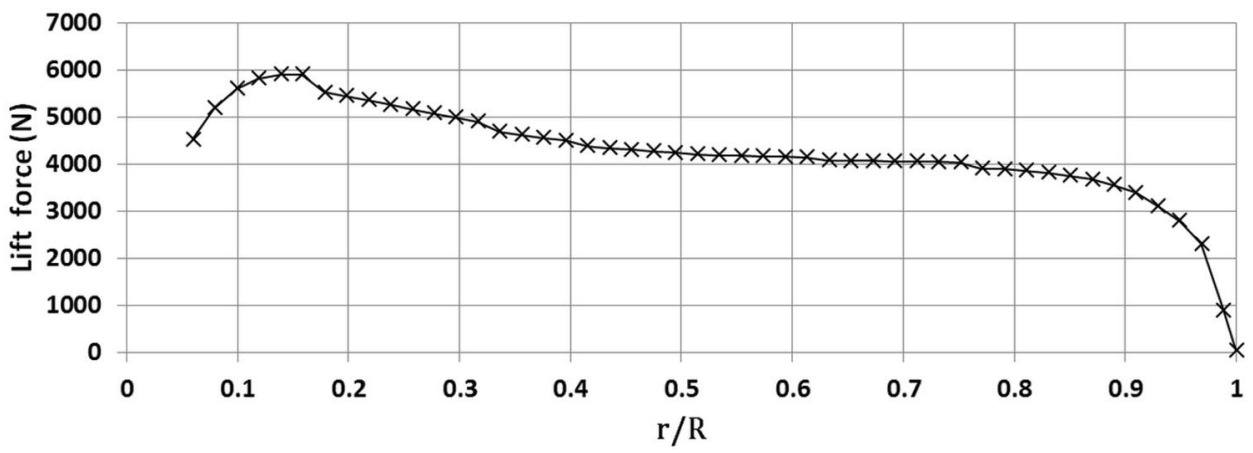

Lift force distribution
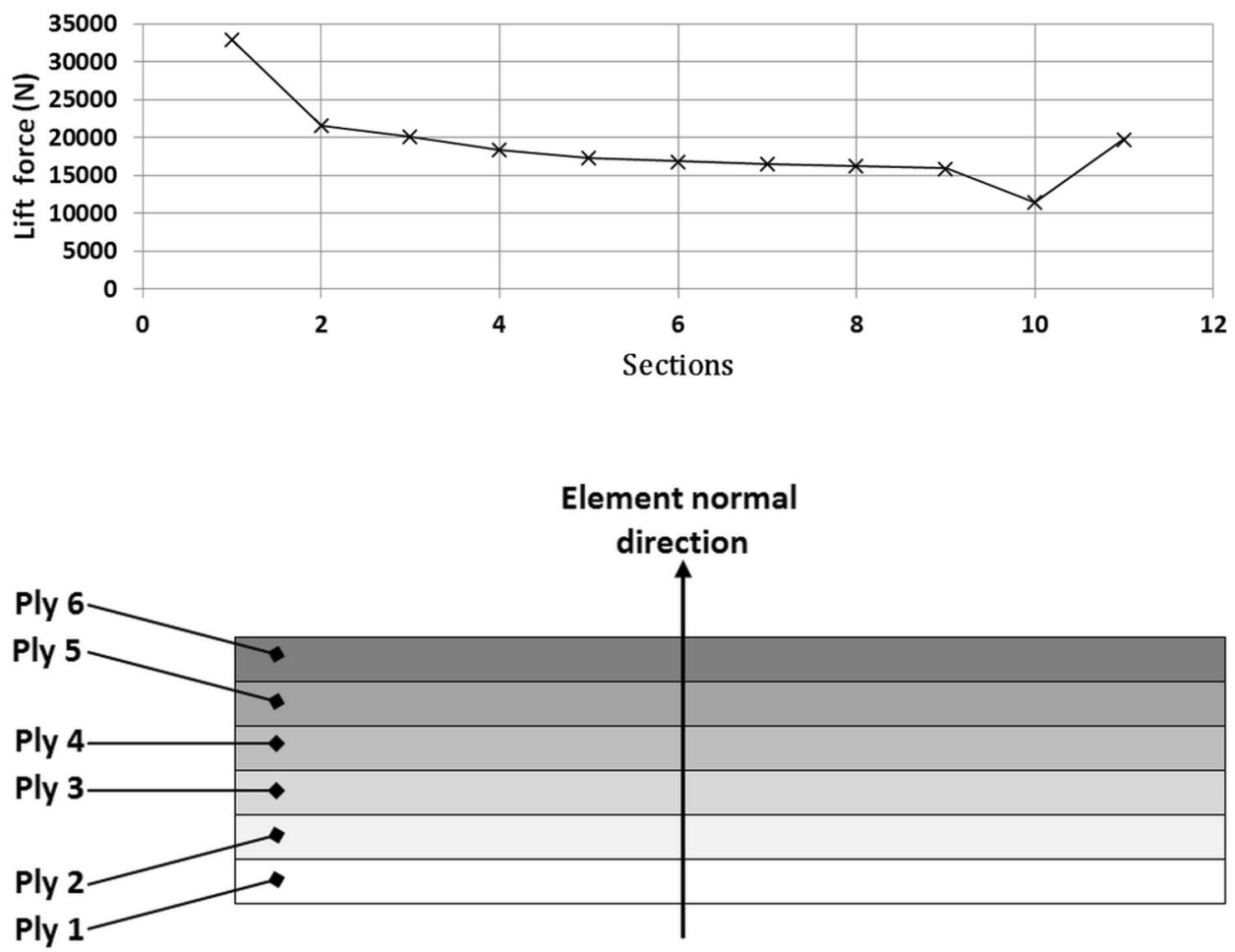

model. PATRAN ${ }^{\circledR}$ Laminate Modeler is well known by its efficiency and simplicity when modeling composites; it allows the user to construct the layup in the same manner that it would be draped in the mold. The model mesh was generated step-by-step using two-dimensional standard quadratic elements capable of representing the plies characteristics throughout the shell thicknesses. A special attention was paid to have a high quality mesh that fit, as much as possible, the complex geometry of the blade, the shape of elements was also checked by verifying the maximum Jacobian Ratio which should be close to one, and finally the normal of elements was verified in order to have an homogeneous normal direction for the entire model, Fig. 13 shows the plies stacking sequence according to the elements normal.
Each set of elements has a particular property defined based on the type of material, the number of layers, their stacking sequence, their orientation angles and their thicknesses, PATRAN ${ }^{\circledR}$ determined the so-called PCOMP to characterize this set of elements. The determination of a material coordinate system is primordial in order to establish the reference of the ply angles. This coordinate system has as third principal axis the normal of element and the two other principal axes are located in the plane of the shell. After definition of material coordinate system of each element, material data listed in Tables 1 and 3 were used to define a planar orthotropic material (MAT8) which were then assigned to the model PCOMPs. 


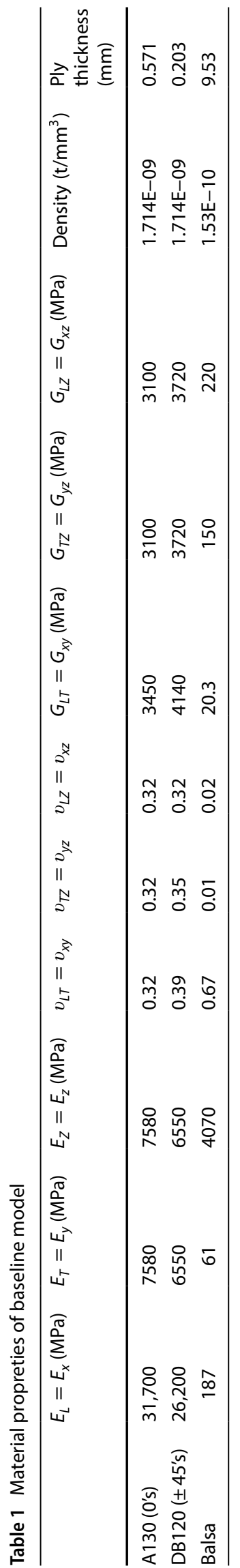

\subsubsection{Boundary conditions and load cases}

The blade is considered as a cantilever beam with a constrained root and a free tip. The contact between the spar caps and the blade middle skin was modelled with a glued contact, an option widely used when the elements mesh size is different between the two surfaces in contact see Fig. 14.

To be conservative, the aerodynamic forces are considered as concentrated forces applied to the extremity of each section of Fig. 8 except for the tip section which is subjected to a force at its middle. The forces are applied using a RBE3 element which allows to transmit efficiently loads from a dependent node also called reference node to an independents nodes also known as master grids. Figure 15 shows the applied load cases and a RBE3 example.

\subsubsection{Static analysis}

Once the mesh was generated, the load cases and the boundary conditions were determined; the models of analysis were exported as databases files to be analyzed using NASTRAN ${ }^{\circledR}$ solver [67]. Results files given by NASTRAN ${ }^{\circledR}$ were to be imported after to PATRAN ${ }^{\circledR}$ for posttreatment.

\subsection{Analytical calculation}

\subsubsection{Blade flexural rigidity}

To get a clear idea about the bending resistance offered by the blade while undergoing aerodynamic loads, the flexural rigidity was calculated based on PATRAN ${ }^{\text {} r e s u l t s . ~}$ Thus, for a given cantilever beam fixed at one extremity, the maximal displacement of this beam can be calculated as showing on (19). So knowing the maximal displacement $y_{\text {Max }}$, the flexural rigidity can be simply deduced.

$y_{\text {Max }}=-\frac{1}{6} \times \frac{F_{\text {force }}}{E I}\left(3 m^{2} I-m^{3}\right)$

where $F_{\text {force }}$ is the applied force, $E$ is the effectif elastic modulus, I represents the effectif moment of inertia and $I$ is the beam length. Figure 16 presents an overview of a beam constrained at one extrimity and submitted to a load $F_{\text {force }}$.

\subsubsection{Criteria for design validation}

The criteria of design verification used through the present work is the allowable tip deflection. For these purposes, the tip clearance should be calculated under ultimate loads and compared to the maximum recommended 
Fig. 14 Spar caps middle skin contact

Fig. 15 Applied forces and RBE3 elements
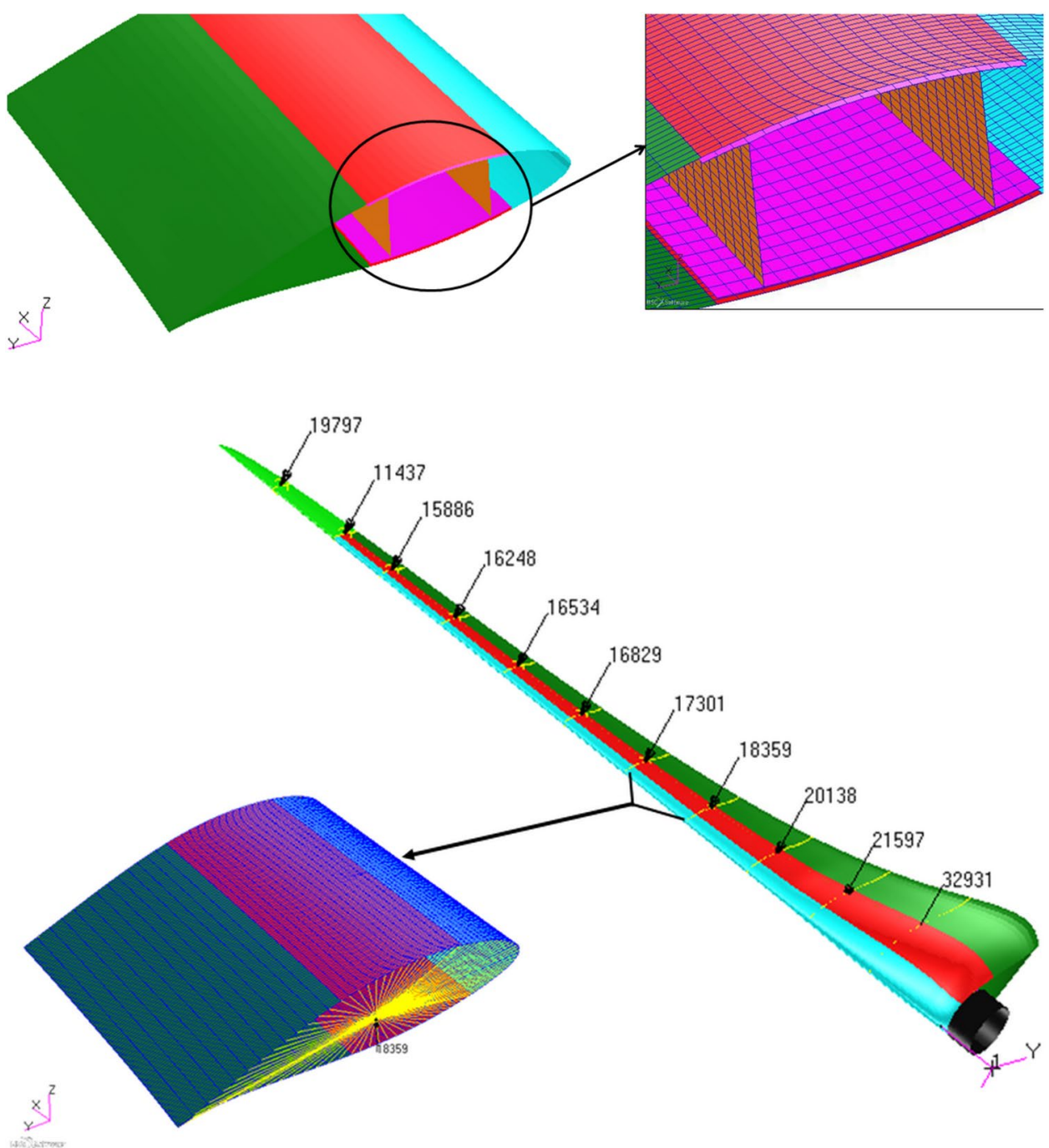

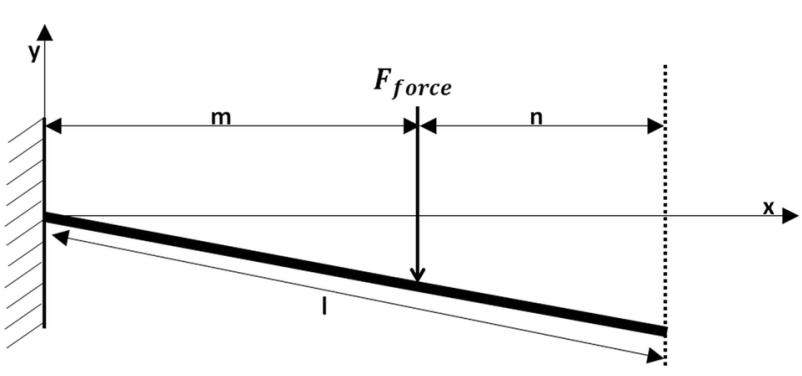

Fig. 16 Deflection of a bending beam

allowable tip deflection that is equal to $0.1 \times R$ as specified in [68].

\section{Results and discussion}

\subsection{Flapwise deflection and flexural rigidities}

The blade rigidity was evaluated in terms of flapwise deflection, hereafter are presented the results obtained for each analyzed model. The material composition of these models has been described in details in Table 2 .

As mentioned before, flexural rigidities were calculated based on the value of the maximal deflection of the blade; Figs. 17 and 18 summarize the obtained results of the tip maximal displacement and the corresponding flexural rigidities.

The turbine radius is equal to $26 \mathrm{~m}$. Thereby, the tip deflection should not exceed $0.1 \times R=2.6 \mathrm{~m}$ [68]. So according to the results shown above, models 3 and 5 can immediately be excluded from analysis as the maximal tip deflection exceeds the allowed limit of $2.6 \mathrm{~m}$. This deficiency was only the consequence of substituting 


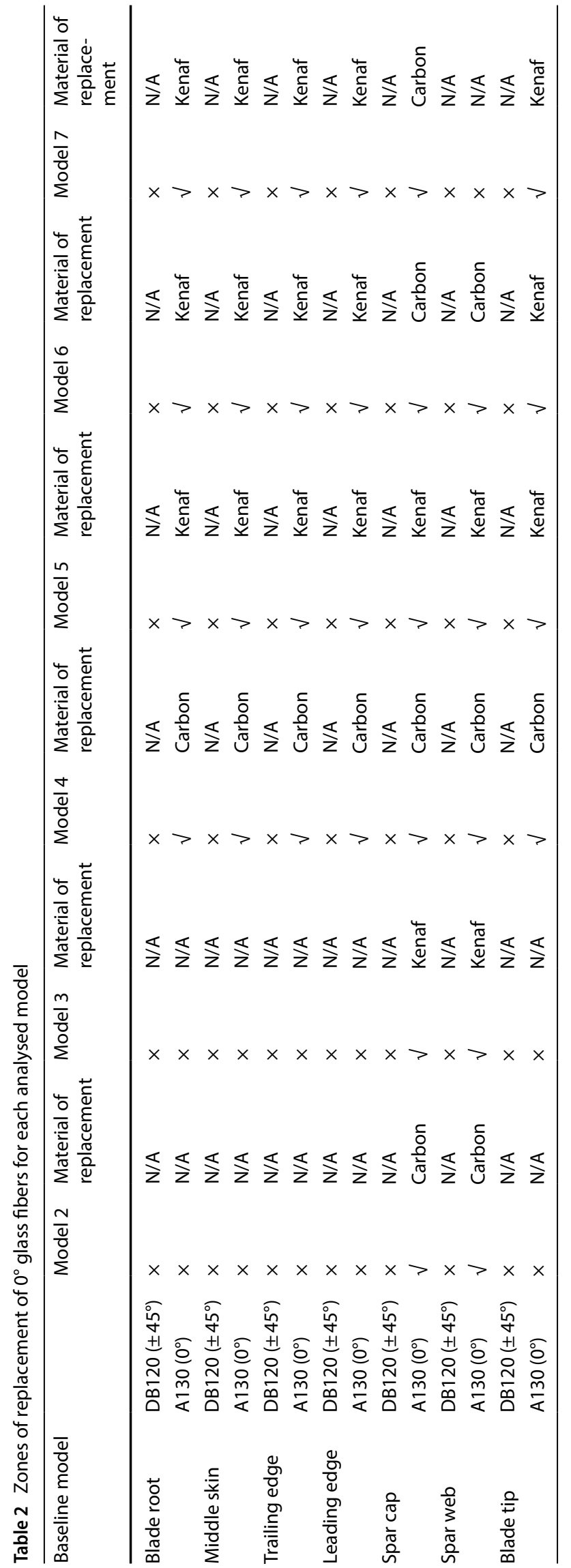

unidirectional glass fibers of the spar with kenaf fibers which led to obtain a model with very low performances. The same thing was observed for model5. In addition, as a consequence of replacing $0^{\circ}$ glass fibers in the blade spar by carbon fibers, model 2 indicated that the tip deflection was reduced by about $40 \%$ and the model became increasingly stiff. For model4, the replacement of all unidirectional glass fibers with carbon fibers provided a model with high rigidity as seen in Fig. 16 and the maximal deflection decreased by $63 \%$ in comparison with the baseline model which was quite predictable if taking into account the high performances of carbon fibers. Instead of replacing all unidirectional glass fibers with kenaf fibers as done for the model 5 and which has given a too elastic model with an unacceptable tip deflection, model 6 was an improved version of model 5 where the same skin structure of model 5 was maintained and unidirectional carbon fibers were introduced into the spar layups, this simple modification helped to obtain a model with a good flexural rigidity which is very close to the one of the baseline model as seen in Fig. 16, and with a maximal deflection of $1.7 \mathrm{~m}$ which represents only $30 \%$ of the reference value. For the sake of further improvement, model 6 was also modified such as the carbon fibers of the web spars were substituted with glass fibers as for the baseline model, resulting in a new model with nearly the same properties as the model 6 while benefiting particularly from an important reduction in materials costs. Many studies in literature show that the hybridization of synthetic composite materials has significant benefits on composite properties. Indeed, Shalwan et al. [69] showed that the introduction of kenaf fibers can improve the tensile strength of polypropylene composite. Juliana et al. [70] investigated that kenaf fibers has good potential as a reinforcement factor for composites made of natural fibers. El-Shekeil et al. [22] proved in his work that hybridization can overcome the disadvantages of the natural fiber reinforced polymer composites such as the fiber-matrix adhesion problem. Aisyah et a. [71] conducted a special analysis to demonstrate that the combination of the carbon with kenaf fibers improves the thermal stability of the resulting hybrid material. Zhafer et al. [72] stated that the stiffness of cellulose, the main component of kenaf fibers, has an important contribution in increasing the tensile modulus of hybrid composite. Davoodi et al. [73] found that hybridization of kenaf with glass fibers improves the mechanical characteristics of natural fiber composite. Ghani et al. [74] observed that the strain to failure of the hybrid composite of kenaf/fiberglass is getting better when it is immersed in water for 3 weeks as this process can make the structure more flexible. Sharba et al. [75] demonstrated that hybrid composites based on kenaf fibers can even improve the fatigue degradation coefficient. 


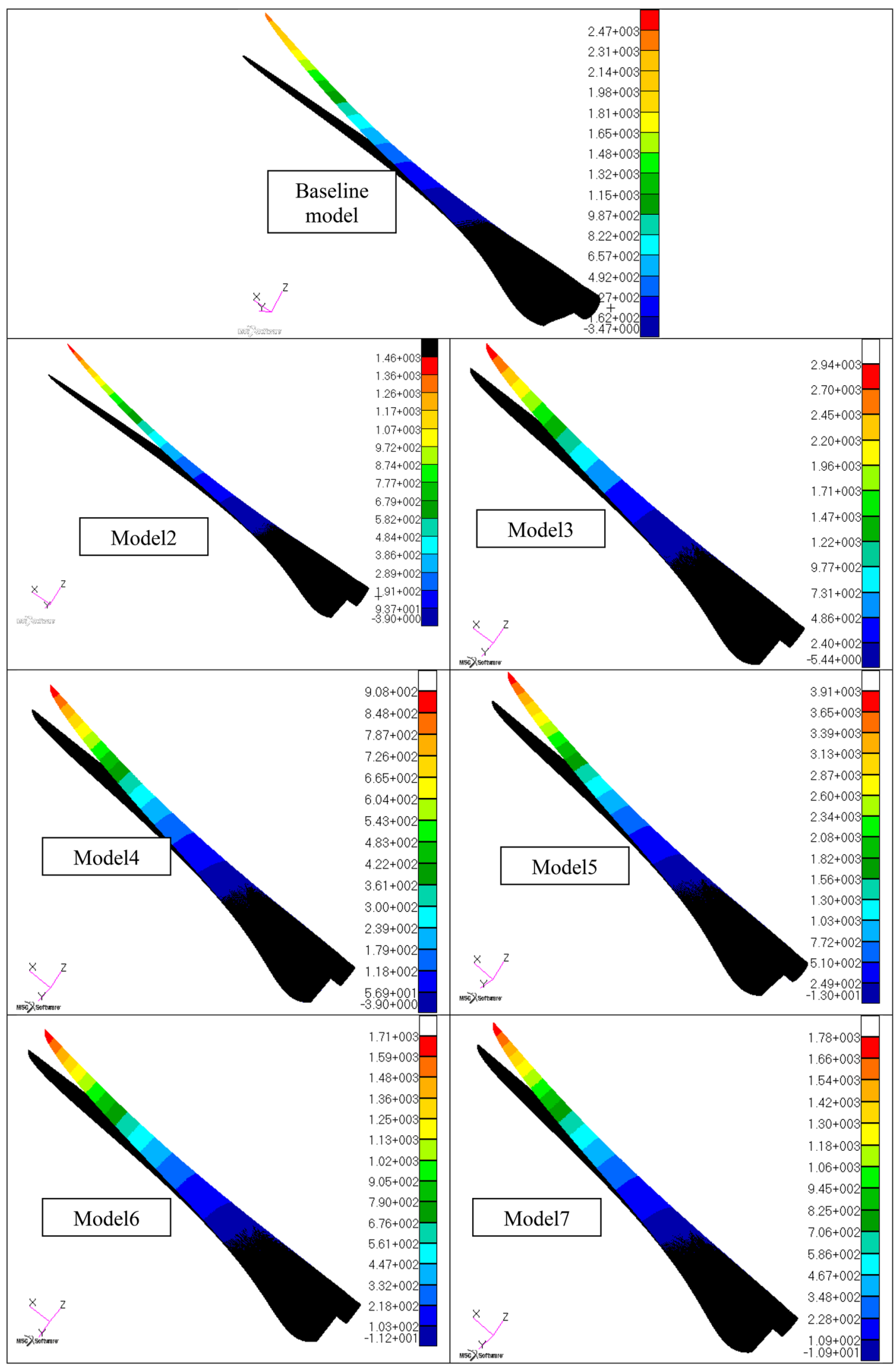

Fig. 17 Models tip deflection results 


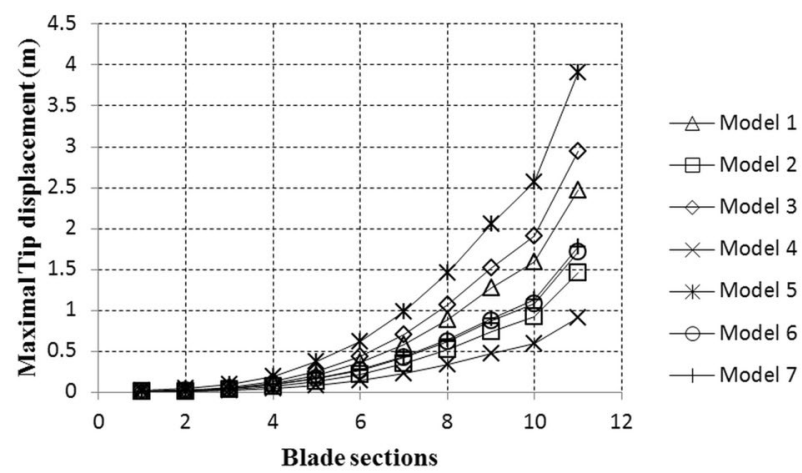

(a)

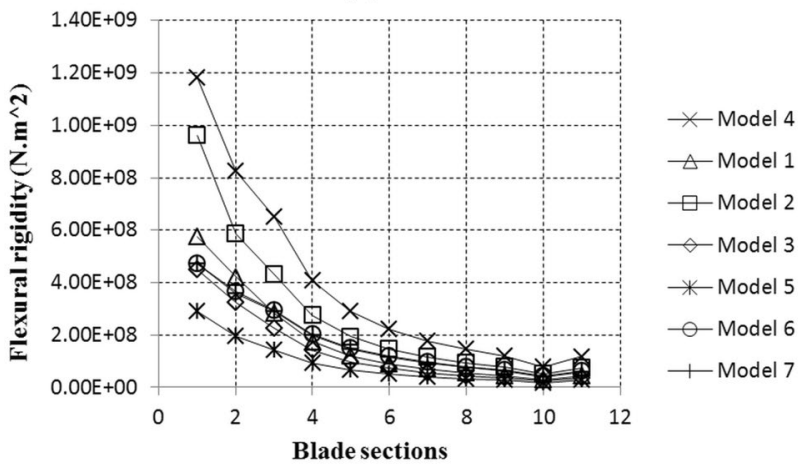

(b)

Fig. 18 Maximal tip deflection and flexural rigidities

\subsection{Models material composition}

For the sake of completeness, below are presented the blades weights of the seven models as well as the percentages of each material weight in the analyzed models.

As seen for the Fig. 19c, analyses were performed so that the percentage of each ply type remains the same for all studied models.

Examining the Fig. 19a, it is noted that the blade mass decreased significantly until reaching a minimum value of $4187 \mathrm{~kg}$ with a reduction rate of about $18 \%$ in comparison with the baseline model. This can be explained by the replacement of $76 \%$ of unidirectional glass fibers with carbon fibers which are characterized by their low density as seen in Table 3. Nearly the same reduction rate $(16.2 \%)$, in terms of blade weight was noted when passing from the baseline model to the models 6 and 7 which was quite predictable as the density of kenaf fibers is very low compared with the one of the glass fibers especially when replacing a significant quantity of fibers as depicted in Fig. 19b, c. Models 2, 3 and 4 also showed a blade mass decrease for the same reasons.

To highlight better the effect of these modifications, an analysis of cost estimation of each blade model was done based on the price per kilogram of fibers. The following table shows an estimated material costs.

Figure 20 summarizes the costs and weight savings for the analyzed models in comparison with the baseline model. From Fig. 20, it can be seen easily that the maximum cost saving was obtained for model5 which was quite logical as the cost of kenaf fibers is 11 times lower than the cost of glass fibers as shown in Table 4 . However, for model 4 , a maximum cost decrease of $161 \%$ was observed compared to the reference model. This was expectable given that the price of carbon fibers is about 3 times the price of glass fibers [79].

\section{Conclusion}

The present report has outlined the impact of introducing carbon and kenaf fibers to a baseline model made by $100 \%$ of epoxy glass fibers. BEM theory was used to determine the design blade and the aerodynamic loads. CATIA ${ }^{\circledR}$ V5 was used to perform the geometry and the software PATRAN $^{\circledR}$ and NASTRAN ${ }^{\circledR}$ were used respectively for creating the finite element model and for launching the analysis calculation.

According to the obtained results, it was noted that in terms of tip deflection only four models that satisfied the condition made for an allowable tip deflection: Models 2, 4, 6 and 7. If we take into account the cost and the weight saving criteria, Models 2, 4 and 6 have to be excluded according to Fig. 20. Therefore, in the end we will have only one model that satisfies all criteria of analysis.

Model7 has shown an acceptable tip deflection with a value of $1.78 \mathrm{~m}$ which presents about $72 \%$ of the baseline maximal flapwise value. As a consequence of replacing the $0^{\circ}$ glass fibers with unidirectional carbon fibers at the 
Fig. 19 Models blades weights and materials compositions

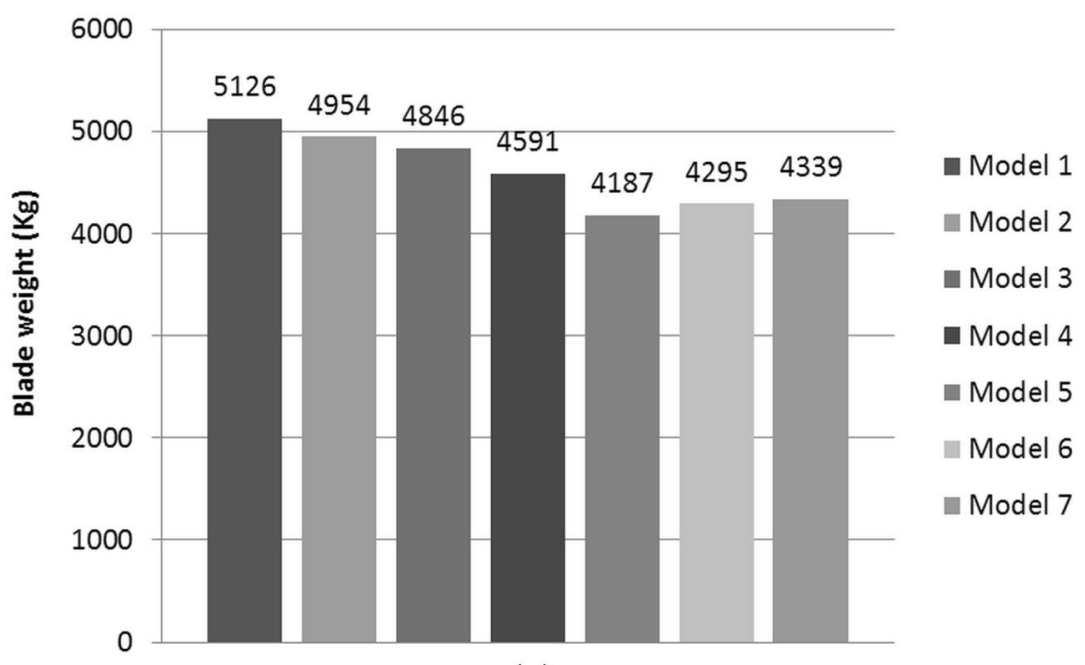

(a)

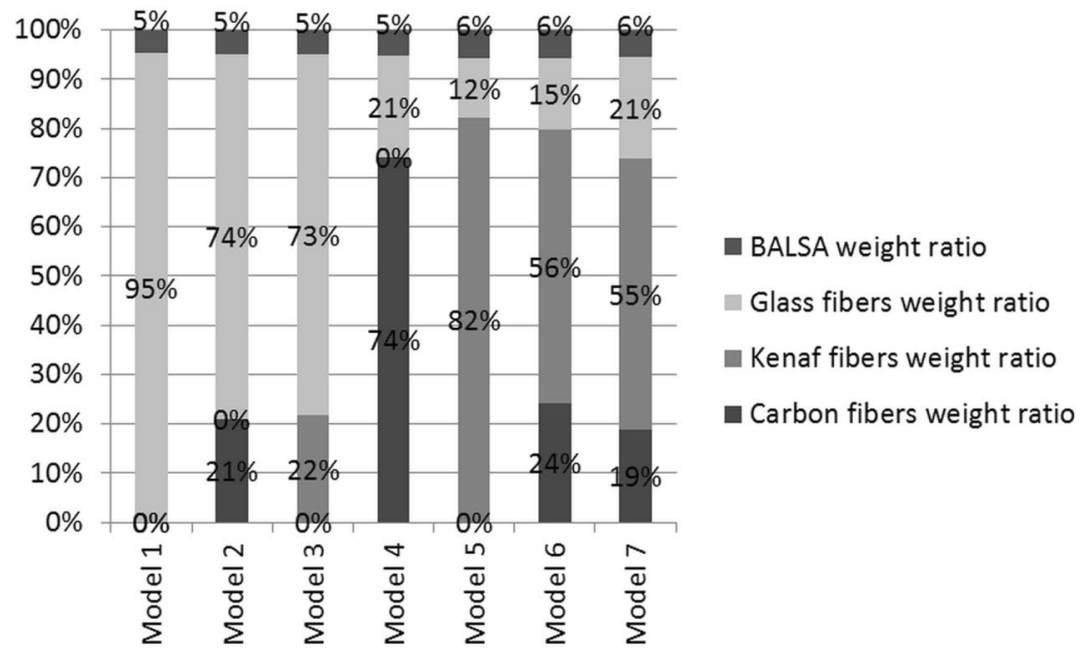

(b)

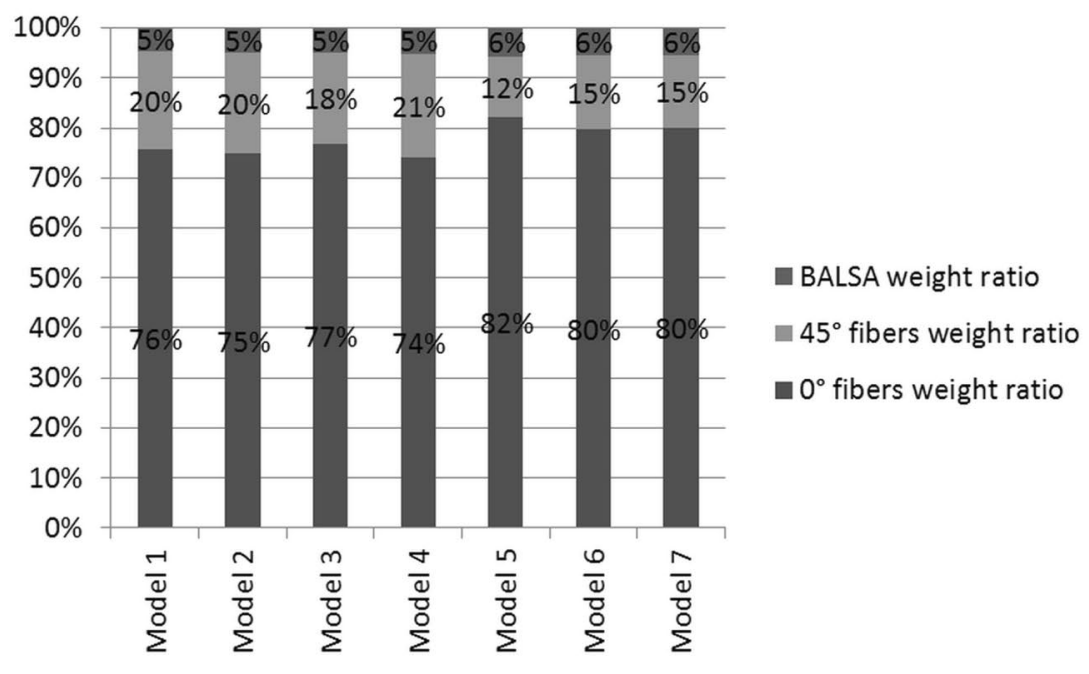

(c) 


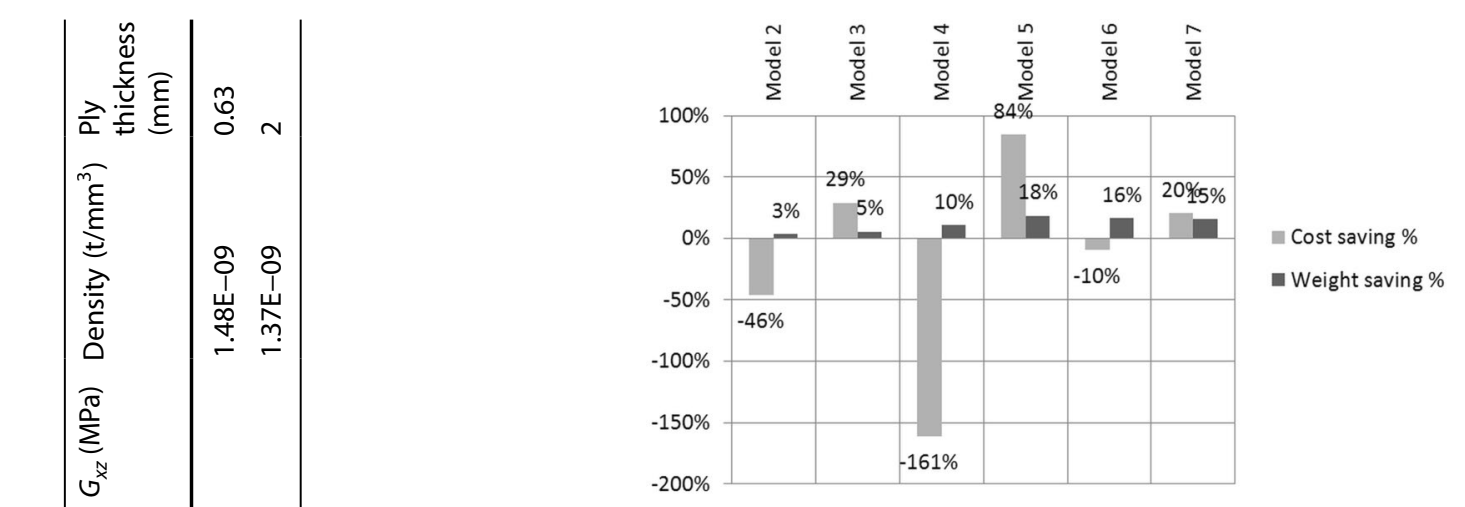

Fig. 20 Models blades costs and weights analyses

Table 4 Estimated meterials costs

\begin{tabular}{lll}
\hline & Cost per $\mathrm{kg}(\$ / \mathrm{kg})$ & References \\
\hline $\begin{array}{l}\text { E-glass prepreg unidirec- } \\
\text { tional }\end{array}$ & 4.1 & {$[76]$} \\
$\begin{array}{l}\text { Carbon prepreg unidirec- } \\
\text { tional }\end{array}$ & 15 & {$[76]$} \\
Kenaf & $\sim 0.35$ & {$[77,78]$} \\
\hline
\end{tabular}

spar caps layups and by unidirectional kenaf fibers at the blade skin, the mass of model7 blade has decreased by a rate of $15 \%$ and the cost of blade, in terms of fibers price, has also decreased by $20 \%$. In addition, with $55 \%$ of kenaf weight ratio which is more than half of the global blade rotor mass, model7 represents also good biodegradable, recyclable and sustainable properties.

Definitely, the proposed model needs some optimizations in terms of blade weight and some structural verification especially fatigue validation. However, this work can provide a significant startup to closely explore the proposed solution.

\section{Compliance with ethical standards}

Conflict of interest The authors declared no potential conflicts of interest with respect to the research, authorship and/or publication of this article.

\section{References}

1. Gwec.net. Global wind reports-GWEC. https://gwec.net/publi cations/global-wind-report-2/. Accessed 1 Aug 2019

2. OFGEM (2018) Renewables obligation: annual report 2016-17 
3. (2008) $20 \%$ wind energy by 2030 , increasing wind energy's contribution to U.S. electricity supply, DOE/GO-102008-2567. http:// www.osti.gov/bridge. Accessed 15 July 2019

4. European Commission (2011) Energy 2020: a strategy for competitive, secure, and sustainable energy [COM(2010)639]. European Union, Luxembourg

5. Zervos A (2009) Renewable energy technology roadmap $20 \%$ by 2020. European Renewable Energy Council, Brussels

6. European Wind Energy Association (2011) EU energy policy to 2050. European Wind Energy Association, Brussels, p 48

7. MARE-WINT (2016) New materials and reliability in offshore wind turbine technology. In: Ostachowicz W, McGugan M, SchröderHinrichs JU Luczak M (eds) Springer, Heidelberg

8. Mishnaevsky L Jr, Brøndsted P, Nijssen RPL, Lekou DJ, Philippidis TP (2012) Materials of large wind turbine blades: recent results in testing and modelling. Wind Energy 15:83-97

9. Ashwill TD(2009) Materials and innovation for large blade structures: research opportunities in wind energy technology. In: 50th AIAA structures, structural dynamics, and materials conference. Palm Springs

10. Kiruthika A (2017) A review on physico-mechanical properties of bast fibre reinforced polymer composites. J Build Eng 9:91-99

11. Ahmad F, Choi HS, Park MK (2015) A review: natural fiber composites selection in view of mechanical, light weight, and economic properties. Macromol Mater Eng 300:10-24

12. Saba N, Paridah MT, Abdan K, Ibrahim NA (2016) Dynamic mechanical properties of oil palm nano filler/kenaf/epoxy hybrid nanocomposites. Constr Build Mater 124:133-138

13. Panigrahi A, Mallick SR (2008) Characterization of hybrid FRP composite with hydrothermal exposure under varied ambient conditions. Department of Metallurgical and Materials Engineering, National Institute of Technology Rourkela, pp 8-10

14. Amroune S, Bezazi A, Belaadi A, Zhu C, Scarpa F, Rahatekar S et al (2015) Tensile mechanical properties and surface chemical sensitivity of technicalfibres from date palm fruit branches (Phoenix dactylifera L.). Compos A Appl Sci Manuf 71:95-106

15. Arthanarieswaran VP, Kumaravel A, Saravanakumar SS (2015) Characterization of new natural cellulosic fiber from Acacia leucophloea bark. Int J Polym Anal Charact 20:367-376

16. Bledzki AK, Franciszczak P, Osman Z, Elbadawi M (2015) Polypropylene biocomposites reinforced with softwood, abaca, jute, and kenaf fibers. Ind Crops Prod 70:91-99

17. Mochane MJ, Mokhena TC, Mokhothu TH, Mtibe A, Sadiku ER, Ray SS, Ibrahim ID, Daramola OO (2019) Recent progress on natural fiber hybrid composites for advanced applications: a review. Express Polym Lett 13(2):159-198

18. Aisyah HA, Paridah MT, Sahri MH, Anwar UMK, Astimar AA (2013) Properties of medium density fibreboard (MDF) from kenaf (Hibiscus cannabinus L.) core as function of refining conditions. Compos Part B Eng 44(1):592-596

19. Saba N, Paridah MT, Jawaid M (2015) Mechanical properties of kenaf fibre reinforced polymer composite: a review. Constr Build Mater 76:87-96

20. International Electrotechnical Commission (1999) IEC 61400-1: wind turbine generator systems-part 1: safety requirements, 2nd edn. International Standard 1400-1

21. Barnes RH, Morozov EV, Shankar K (2015) Evaluation of simplified loading models for finite element analysis of composite wind turbine blades. In: Proceedings of the 20th international conference on composite materials (ICCM-20), Copenhagen, 19-24 July

22. El-Shekeil YA, Sapuan SM, Jawaid M, Al-Shuja'a OM (2014) Influence of fiber content on mechanical, morphological and thermal properties of kenaf fibers reinforced poly (vinyl chloride)/thermoplastic polyurethane poly-blend composites. Mater Des 58:130-135
23. Yahaya R, Sapuan SM, Jawaid M, Leman Z, Zainudin ES (2014) Mechanical performance of woven kenaf-Kevlar hybrid composites. J Reinf Plast Compos 33(24):2242-2254

24. Zhang Y, Li Y, Ma H, Yu T (2013) Tensile and interfacial properties of unidirectional flax/glass fiber reinforced hybrid composites. Compos Sci Technol 88:172-177

25. Niedermann P, Szebényi G, Toldy A (2015) Characterization of high glass transition temperature sugarbased epoxy resin composites with jute and carbon fibre reinforcement. Compos Sci Technol 117:62-68. https://doi.org/10.1016/j.compscitec h.2015.06.001

26. Khanam PN, Khalil HA, Jawaid M, Reddy GR, Narayana CS, Naidu SV (2010) Sisal/carbon fibre reinforced hybrid composites: tensile, flexural and chemical resistance properties. J Polym Environ 18(4):727-733

27. Romanzini D, Lavoratti A, Ornaghi HL Jr, Amico SC, Zattera AJ (2013) Influence of fiber content on the mechanical and dynamic mechanical properties of glass/ramie polymer composites. Mater Des 47:9-15. https://doi.org/10.1016/j.matde s.2012.12.029

28. Dhakal HN, Zhang ZY, Guthrie R, MacMullen J, Bennett N (2013) Development of flax/carbon fibre hybrid composites for enhanced properties. Carbohydr Polym 96(1):1-8

29. Jarukumjorn K, Suppakarn N (2009) Effect of glass fiber hybridization on properties of sisal fiber-polypropylene composites. Compos B Eng 40(7):623-627

30. Moriarty PJ, Hansen AC (2005) AeroDyn theory manual. National Renewable Energy Laboratory, Golden

31. Burton T, Sharpe D, Jenkins N, Bossanyi E (2001) Wind energy handbook. Wiley, Chichester

32. Hansen MOL (2008) Aerodynamics of wind turbines. Earthscan, London

33. Duquette MM, Visser KD (2003) Numerical implications of solidity and blade number on rotor performance of horizontal-axis wind turbines. J Sol Energy Eng 125:425

34. Airfoil Tools http://airfoiltools.com. Accessed 3 Feb 2019

35. Public Domain Aeronautical Software (PDAS) http://www. pdas.com/sections6.html\#s63618. Accessed 1 Feb 2019

36. Wind Energy Market Intelligence (2019) http://www.thewi ndpower.net/turbine_fr_42_gamesa_850.php. Accessed 15 Mar 2019

37. Brøndsted P, Nijssen R (eds) (2013) Advances in wind turbine blade design and materials. Woodhead Publishing, Oxford, $p$ 484

38. Ganesh RK, Rajashekar P, Narayan N (2016) Natural fiber reinforced polymer composite materials for wind turbine blade applications. Int J Sci Dev Res 1(9):28-37

39. Lobitz DW et al (2001) The use of twist-coupled blades to enhance the performance of horizontal axis wind turbines. SAND2001-1303. Sandia National Laboratories, Albuquerque

40. Ong CH, Tsai SW (2000) The use of carbon fibers in wind turbine blade design: a SERI-8 blade example. SAND 2000-0478. Sandia National Laboratories, Albuquerque

41. Zuteck M (2002) Adaptive blade concept assessment: curved planform induced twist investigation. SAND2002-2996. Sandia National Laboratories, Albuquerque

42. Locke J, Hidalgo IC (2002) The implementation of braided composite materials in the design of a bend-twist coupled blade. SAND2002-2425. Sandia National Laboratories, Albuquerque

43. Griffin DA (2002) Evaluation of design concepts for adaptive wind turbine blades. SAND2002-2424. Sandia National Laboratories, Albuquerque

44. Reis PNB, Ferreira JAM, Antunes FV, Costa JDM (2007) Flexural behaviour of hybrid laminated composites. Compos Part A Appl S 38:1612-1620 
45. Panthapulakkal S, Sain M (2007) Studies on water absorption properties of short-hemp glass fiber hybrid polypropylene composites. J Compos Mater 41:1871-1883

46. Daniel IM, Ishai $O$ (2006) Engineering mechanics of composite materials, 2nd edn. Oxford University Press, New York

47. Brondsted $\mathrm{P}$, Lilholt $\mathrm{H}$, Lystrup $\mathrm{A}$ (2005) Composite material for wind power turbine blades. Annual Reviews, Roskilde

48. Watt W, Perov PV (1985) Strong fibres. In: Kelly A, Rabotnov YN (eds) Handbook of composites. North-Holland/Elsevier, Amsterdam, $\mathrm{p} 755$

49. Bunsell AR (1988) Fibre reinforcements for composite materials. Elsevier, Amsterdam, p 537

50. Chou TW (2000) Fibre reinforcements and general theory of composites. See Ref 95(1):802

51. Paridah MT, Basher AB, SaifulAzry S, Ahmed Z (2011) Retting process of some bast plant fibres and its effect on fibre quality: a review. BioResources 6(4):5260-5281

52. Ahmad AM, Jalaluddin H, Paridah MT, Resalati $H$, Rushdan I, Shamsi SRF, Ainun ZM (2010) A review of literatures related of using kenaf for pulp production (beating, fractionation, and recycled fiber). Modern Appl Sci 4(9):21-29

53. Saba N, Paridah T, Jawaid M (2015) Potential utilization of kenaf biomass in different application. In: Hakeem K, Jawaid M, Alothman $\mathrm{O}$ (eds) Agricultural biomass based potential materials. Springer, Cham, pp 1-34

54. Ramesh P, Durga Prasad B, Narayana K (2018) Characterization of kenaf fiber and its composites: a review. J Reinf Plast Compos 37(11):731-737

55. Faruk O, Bledzki AK, Fink H-P, Sain M (2012) Biocomposites reinforced with natural fibers: 2000-2010. Prog Polym Sci 37(11):1552-1596

56. Nishino T, Hirao K, Kotera M, Nakamae K, Inagaki H (2003) Kenaf reinforced biodegradable composite. Compos Sci Technol 63:1281-1286

57. Summerscales J et al (2010) A review of bast fibres and their composites. Part 1-fibres as reinforcements. Compos Part A Appl Sci Manuf 41(10):1329-1335

58. Elsaid A, Dawood M, Seracino R, Bobko C (2011) Mechanical properties of kenaf fiber reinforced concrete. Constr Build Mater 25:1991-2001

59. Dinesh V, Shivanand HK, Vidyasagar HN, Srinivasa Chari V (2018) Investigation of mechanical properties of kenaf, hemp and E-glass fiber reinforced composites. AIP Conf Proc 1943:020117

60. Hamidon MH, Sultan MTH, Ariffin AH, Shah AUM (2019) Effects of fibre treatment on mechanical properties of kenaf fibre reinforced composites: a review. J Mater Res Technol 8:3327-3337

61. McKittrick LR, Cairns DS (2001) Analysis of a composite blade design for the AOC15/50 wind turbine using a finite element mode. SANDIA Report, SAND2001-1441

62. Berry S, Lockard S (2002) Parametric study for large wind turbine blades. SAND 2002-2519, Unlimited Release Printed

63. Kong C, Bang J, Sugiyama Y (2005) Structural investigation of composite wind turbine blade considering various load cases and fatigue life. Energy 30:2101-2114
64. Bir G, Migliore P (2004) Preliminary structural design of composite blades for two- and three-blade rotors, NREL/TP-500-31486. National Renewable Energy Laboratory, Golden

65. Sapuan SM, Ishak MR, Sahari J, Sanyang ML (2018) Kenaf fibers and composites. CRC Press, Boca Raton

66. Dan-mallam Y, Abdullah MZ, MegatYusoff Puteri S M (2012) Predicting the tensile properties of woven kenaf/polyethylene terephthalate (PET) fiber reinforced polyoxymethylene (POM) hybrid laminate composite. IOSR J Mech Civ Eng IOSRJMCE 2(3):06-13

67. MD/MSC NASTRAN 2010 (2010) Quick reference guide. MSC Software

68. Grujicic M, Arakere G, Pandurangan B, Sellappan V, Vallejo A, Ozen M (2010) Multidisciplinary optimization for fiber-glass reinforced epoxy-matrix composite $5 \mathrm{MW}$ horizontal-axis windturbine blades. J Mater Eng Perform 19:1116-1127

69. Shalwan A, Yousif BF (2013) In state of art: mechanical and tribological behaviour of polymeric composites based on natural fibers. Mater Des 48:14-24

70. Juliana AH, Aisyah HA, Paridah MT, Adrian CCY, Lee SH (2018) Kenaf fiber: structure and properties. In: Sapuan SM, Ishak JR, Sahari J, Sanyang ML (eds) Kenaf fibers and composites, 1st edn. CRC Press, Boca Rotan, pp 23-36. https://doi.org/10.1201/97813 51050944

71. Aisyah HA, Paridah MT, Khalina A, Sapuan SM, Wahab MS, Berkalp OB, Lee CH, Lee SH (2018) Effects of fabric counts and weave designs on the properties of laminated woven kenaf/ carbon fibre reinforced epoxy hybrid composites. Polymers 10(12):1320. https://doi.org/10.3390/polym 10121320

72. Zhafer SF, Rozyanty AR, Shahnaz SBS, Musa L, Zuliahani A (2016) Kenaf-glass fiber reinforced unsaturated polyester hybrid composites. Tensile Prop. https://doi.org/10.1063/1.4958770

73. Davoodi MM, Sapuan SM, Ahmad D et al (2010) Mechanical properties of hybrid kenaf/glass reinforced epoxy composite for passenger car bumper beam. Mater Des 31:4927-4932

74. Ghani MAA, Salleh Z, Hyie KM et al (2012) Mechanical properties of kenaf/fiber glass polyester hybrid composite. Proc Eng 41:1654-1659

75. Sharba MJ, Leman Z, Sultan MTH, Ishak MR, Hanim MAA (2015) Effects of kenaf fiber orientation on mechanical properties and fatigue life of glass/kenaf hybrid composites. BioResources. https://doi.org/10.15376/biores.11.1.1448-1465

76. Dayton A (2002) Griffin, blade system design studies volume I: composite technologies for large wind turbine blades, SAND2002-1879

77. Alma Hodzic RS (ed) (2013) Natural fibre composites: materials, processes and applications. Elsevier, Amsterdam

78. Mohammed $L$ et al (2015) A review on natural fiber reinforced polymer composite and its applications. Int J Polym Sci 2015:15

79. Felipe S, Veronica C, Nei P Jr (2018) Lignin-based carbon fiber: a current overview. Mater Res Express 5(7):1-55

Publisher's Note Springer Nature remains neutral with regard to jurisdictional claims in published maps and institutional affiliations. 